\title{
O QUE PODE UM CURRÍCULO? BREVE ENSAIO SOBRE O CURRÍCULO EM IMANÊNCIA
}

\author{
¿QUÉ PUEDE HACER UN CURRÍCULUM? BREVE ENSAYO SOBRE EL \\ CURRÍCULUM EN INMANENCIA.
}

\author{
WHAT CAN A CURRICULUM DO? BRIEF ESSAY ON THE CURRICULUM IN \\ IMMANENCE
}

\author{
Dinamara Garcia FELDENS ${ }^{1}$ \\ Camilo CATANHEDE ${ }^{2}$ \\ Luana FUSARO ${ }^{3}$
}

RESUMO: Este artigo, escrito a partir de discussões e leituras entre os autores, membros do grupo de pesquisa Educação, Cultura e Subjetividades (GPECS/CNPq/UFS), e desenvolvido através da dissertação de Mestrado de um dos autores, propõe uma reflexão sobre aspectos da teoria de Baruch de Spinoza para compor diferentes modos de educar. Busca-se considerar um currículo que extrapole os modelos tradicionais, e que esteja comprometido em produzir uma educação potencializada por afetos alegres. Neste sentido perguntamos: o que pode um currículo? Para pensar sobre esta questão, iremos utilizar os resultados sistematizados de uma pesquisa de experimentações curriculares, realizada durante quase três anos, em uma escola localizada no estado de Sergipe. Além Spinoza, traremos no referencial teórico conceitos de Gilles Deleuze e Félix Guattari e a ideia de nomadismo curricular de Sandra Mara Corazza. Com essa articulação, buscamos demonstrar alguns princípios e práticas que convergem à uma educação amorosa, composta por afetos alegres, capaz de aumentar a potência e a intensidade do pensamento e da aprendizagem.

PALAVRAS-CHAVE: Educação. Nomadismo curricular. Necropolítica. Afetos.

RESUMEN: Este artículo, elaborado a partir de discusiones y lecturas entre los autores, miembros del grupo de investigación Educación, Cultura y Subjetividades (GPECS/CNPq/UFS), y desarrollado a través de la tesis de maestría de uno de los autores, propone una reflexión sobre los aspectos de la teoría de Baruch de Spinoza para componer diferentes formas de educar. El objetivo es plantear un currículum que vaya más allá de los modelos tradicionales, y que apueste por producir una educación enriquecida con afectos felices. En este sentido nos preguntamos: ¿qué puede hacer un currículum? Para reflexionar

\footnotetext{
${ }^{1}$ Universidade Federal de Sergipe (UFS), Aracaju - SE - Brasil. Professora Permanente do Programa de PósGraduação em Educação. Doutorado em Educação Básica (UNISINOS). ORCID: https://orcid.org/0000-00013876. E-mail: dinag.feldens@gmail.com

${ }^{2}$ Universidade Federal de Sergipe (UFS), Aracaju - SE - Brasil. Mestrado pelo Programa de Pós-Graduação em Educação. Membro do Grupo de Pesquisa Educação, Cultura e subjetividades. GPECS/CNPq/UFS. ORCID: https://orcid.org/0000-0002-9391-8210. E-mail: camiloeumesmo@gmail.com

${ }^{3}$ Pontifícia Universidade Católica de São Paulo (PUC-SP), São Paulo - SP - Brasil. Doutoranda no Programa de Pós-Graduação em Comunicação e Semiótica. Membro do Grupo de Pesquisa Educação, Cultura e subjetividades. GPECS/CNPq/UFS. ORCID: https://orcid.org/0000-0002-6481-2935. E-mail: luafeldens@gmail.com
}

RIAEE - Revista Ibero-Americana de Estudos em Educação, Araraquara, v. 16, n. 4, p. 2826-2851, out./dez. 2021. e-ISSN: 1982-5587 DOI: https://doi.org/10.21723/riaee.v16i4.15689 
sobre esta cuestión, utilizaremos los resultados sistematizados de una encuesta de experimentos curriculares, realizada durante casi tres años, en una escuela ubicada en el estado de Sergipe. Además de Spinoza, traeremos los conceptos del marco teórico de Gilles Deleuze y Félix Guattari y la idea de nomadismo curricular de Sandra Mara Corazza. Con esta articulación, buscamos demostrar unos principios y prácticas que convergen hacia una educación amorosa, compuesta de afectos alegres, capaces de incrementar el poder y la intensidad del pensamiento y el aprendizaje.

PALABRAS CLAVE: Educación. Nomadismo curricular. Necropolíticas. Afectos.

ABSTRACT: This paper, written from discussions and readings among the authors, members of the Education, Culture and Subjectivities research group (GPECS/CNPq/UFS), and developed through the Master's thesis of one of the authors, proposes a reflection on the aspects from the theory of Baruch de Spinoza to compose different ways of educating. The aim is to consider a curriculum that goes beyond traditional models, and that is committed to producing an education enhanced by happy affections. In this sense we ask: what can a curriculum do? To think about this question, we will use the systematized results of a survey of curricular experiments, carried out for almost three years, in a school located in the State of Sergipe. In addition to Spinoza, we will bring in the theoretical framework concepts by Gilles Deleuze and Félix Guattari and the idea of curricular nomadism by Sandra Mara Corazza. With this articulation, we seek to demonstrate some principles and practices that guides to a loving education, composed of happy affections, capable of increasing the power and intensity of thought and learning.

KEYWORDS: Education. Curricular nomadism. Necropolitics. Affections.

\section{Introdução - A busca por um modo de educar afetivo}

A reflexão proposta neste artigo se inicia através de uma pesquisa com membros do Grupo de Pesquisa Educação, Cultura e Subjetividades, e traçou o percurso investigativo da dissertação de um dos autores deste artigo, partindo da seguinte questão: como o currículo pode auxiliar na transformação de realidades na busca ativa por afetos de alegria e amor? Naquela ocasião conceituamos o processo de criação e constituição de um modo de educar que atualizava o currículo enquanto aprendíamos a escutar e considerar os desejos, alegrias, tristezas e curiosidades do corpo discente na concepção e organização de relações de ensino e aprendizagens afetivas dentro e fora da escola.

Explicamos como saímos de currículo centrado no decalque de informações e encontramos um caminho em direção a outro tipo de currículo, que vaga por mundos de quem vive a aprender. São dois modos distintos de viver a arte de educar. Um que privilegia o decorar, a reprodução de informações, a repetição de questões pré-concebidas, a preparação para testes e provas padronizados e, por fim, a uniformização da comunicação entre o corpo 
docente e suas turmas. Noutra perspectiva, temos uma educação que liberta o pensamento do decalque em atos de criação repletos de desejos de aprender. Um modo que cerceia a curiosidade do corpo que aprende ao viver "com": conviver nas dinâmicas familiares, conviver a vizinhança, com a rua, o sol, a chuva, a fazenda, o bairro, em suma, com a realidade na qual a escola está inserida. Outro modo que leva em consideração o que afeta o corpo aprendiz e desperta o desejo de conhecer e criar do corpo que vive e aprende de modo singular na coletividade da realidade que toca.

Perguntamos o que pode um currículo com o objetivo de encontrar caminhos para incluir a realidade vivida pelo corpo que aprende na concepção e organização de relações de ensino e aprendizagem afetivas, potentes e, por que não, imediatamente úteis ao corpo que aprende? Já saímos daquele lugar de professor que tudo sabe, muito repete, muito fala, pouco escuta, pouco transforma, pouco cria, pouco deixa criar.

Ainda buscamos explicar que a saída do lugar de decalque só foi possível quando aprendemos a considerar o papel pedagógico do desejo, da alegria e da tristeza na educação que praticávamos. Os caminhos tomados a partir de uma nova ênfase da arte de educar nos conduziram a um modo de construir juntos e elaborar projetos pedagógicos de curta duração em sintonia com o desejo de aprender do corpo discente.

Neste sentido, criamos um pequeno projeto que transformou uma realidade de tristeza determinada por mecanismos de deterioração da existência humana em afetos e uma realidade de alegria - e que aconteceu fora da escola. Tudo começou em uma roda de conversa convocada por crianças e adolescentes que direta ou indiretamente participavam da oficina Horta Ecológica, inserida na matriz curricular da escola onde trabalhava um dos autores deste artigo.

A oficina, obrigatória, foi de onde partimos. Depois de mais de dois anos de caminhada, chegamos à última experimentação curricular em um projeto pedagógico mais ousado. O projeto envolvia a recuperação de sala abandonada em um povoado localizado às margens de um lixão irregular que concentrava a maioria dos casos de assassinatos de familiares de estudantes matriculados na escola. Em meio a diferentes modos de promover a deterioração da existência humana na realidade onde viviam, as crianças vislumbraram uma realidade passível de transformação. Um futuro possível mais alegre que perpassava a conquista de um lugar para brincar em segurança.

O projeto acontecia fora da escola. As atividades programadas ocorriam sem obrigação, lista de presença ou qualquer instrumento de penalização similar aos utilizados na escola - como advertência escrita endereçada a familiares, suspensão ou expulsão. Uma vez 
por semana, fora do extenso horário da educação integral, o jovem coletivo se reunia para dar conta das metas estabelecidas no projeto. Com doações e ajuda de moradores do povoado levamos quase três meses para recuperar a sala e ocupar o espaço com uma singela brinquedoteca e biblioteca.

O projeto de revitalização da sala deu origem à Segunda Casa, nome dado pelas crianças ao espaço após conquistado o lugar que enxergaram possível: um espaço onde pudessem brincar e se divertir com segurança. Ao final do projeto Segunda Casa, chegamos a uma proposta de manejo afetivo de relações de ensino e aprendizagem transformadoras. Com essa proposta de manejo, em conjunto com princípios e práticas da pedagogia de projetos que, grosseiramente, consiste em utilizar do arcabouço teórico e metodológico da gestão de projetos na arte de educar -, o currículo que praticávamos se atualizava em projetos pedagógicos afetivos ancorados nas diferentes realidades vividas por quem aprendia (CANTANEDE; LIBÓRIO, 2017).

As intervenções do coletivo Segunda Casa são planejadas, realizadas e avaliadas com o uso de quatro Metodologias: planejamento participativo-PP, rodada de avaliação do método Campesino à Campesino-CaC, instalação artístico pedagógica-IAP e sistematização gráfica-SG. Todas as Metodologias utilizadas foram escolhidas pelo viés participativo e por estimularem ou facilitarem momentos pautados pelo diálogo horizontalizado (CANTANHEDE; LIBÓRIO, 2018, p. 02).

Posteriormente, descreveremos o papel de cada ferramenta citada acima nas atualizações do currículo. Por hora nos basta destacar que a integração das ferramentas metodológicas acima consolidou a proposta de manejo afetivo das relações de ensino e aprendizagem. Por sua vez, essa mesma proposta fez a nossa arte de educar capaz de mobilizar o corpo discente na transformação daquilo que era causa de alegria e promover aprendizados úteis na conquista de alegrias possíveis.

Um currículo passa por diferentes processos antes de encontrar um modo de acolher afetos do corpo que aprende e se tornar capaz de causar alegria, amor e união por vínculos de amizade. Chamamos de currículo em imanência o estado no qual o processo educativo sintoniza aquilo que devemos ensinar - BNCC - ao desejo de criar a aprender do corpo discente. Nesse estado, o corpo discente está mobilizado em aprendizados repletos de significados e utilidade para si e, concomitantemente, a arte de educar passa a prescindir de estímulos externos - sejam eles de alegria ou de tristeza - ao corpo que aprende.

Se a educação assume o desafio de fazer frente a modos variados de promover a deterioração da existência, o conceito de necropolítica, cunhado pelo filósofo e historiador 
camaronês Achille Mbembe (2018), pode ser útil. Ele definiu o conceito como o poder de determinar quem deve viver, quem deve ser mais ou menos exposto a riscos de morte e, em última instância, quem devemos deixar morrer.

No livro Necropolítica ele explica como essa construção social participou do processo de criação dos mecanismos de regulação e coesão social de formações de poder instituídas nas sociedades modernas. A necropolítica pode, assim, ser compreendida como um processo singular e coletivo que se inicia com a negação da condição humana e perpassa a criação de inimigos. É justamente a criação de um ou mais inimigos que legitimam políticas de inimizade e/ou perseguições que sustentam políticas de morte. São elas que dão rosto e cor ao corpo que morrerá, porque aprendemos a tolerar sua morte a partir da indiferença.

Embora em sua origem o conceito tenha sido limitado a determinadas situações especificadas na obra de Mbembe, hoje seu uso se expandiu para fora da academia e nos permite pensar nosso tempo de maneira mais complexa. Fizemos uso do conceito na explicação do processo de criação de uma base curricular útil no desarme de políticas de morte. Contudo, em decorrência de tantas políticas de mortes incidentes sobre as linhas de força da educação, como organizar o pensamento e planejar o esforço pedagógico para proporcionar o aprendizado determinado pelo currículo nacional e, ainda, fazer frente às necropolíticas que enfrentamos dentro e fora da escola? Como podemos tornar o trabalho pedagógico causa de alegria na conquista de mudanças desejadas?

Como conciliar as expectativas da família, da criança e das forças sociais que afetam a educação que podemos e devemos ofertar? O que a escola e o currículo podem e devem ensinar, propor e desejar? Como conciliar tantos desejos em uma proposta pedagógica que se pretende transformadora? O que devemos priorizar em um processo que almeja transformar realidades causadoras de tristezas em realidades contrárias, que sejam causa de alegria e contentamento?

Diante de tantos problemas que se agravam em nosso tempo, o que, efetivamente, um currículo e uma comunidade escolar podem transformar? De todo conhecimento já produzido e acumulado pela humanidade, qual conjunto de ideias, conceitos, teorias, princípios, práticas, tecnologias devemos ensinar?

Como interagir com forças que sem o objetivo explícito de ensinar - para o bem e para mal - também ensinam tantas coisas? A família e seus hábitos educam. A televisão, as redes sociais, a rua, a comunidade, a classe política, as expectativas da sociedade e dos grupos sociais por onde circulamos também afetam o processo educativo. 
São inúmeras as questões a serem discutidas, mas buscamos discutir e propor princípios e práticas que nos orientem na criação de modos de educar capazes de ensinar aos corpos - discentes e docentes - a pensar, agir e ensinar segundo ideias adequadas. Quer dizer, fazer bom uso da razão para aumentar o potencial de ação individual e coletivo em propostas pedagógicas capazes de transformar causas de tristeza e ódio em causas de afetos contrários, de alegria e amor.

\section{Proposições para um currículo em imanência}

As proposições aqui apresentadas são fruto de composições teóricas que referenciam este texto e discussão entre os autores. Ancoradas na realidade da experiência pedagógica descrita acima, as proposições ou princípios para um currículo em imanência funcionam como um mapa de forças para sintonizar as relações de ensino e aprendizagens aos desejos de aprender do corpo discente. Sem nenhuma pretensão universalista, os princípios explicados a seguir nos orientam por caminhos que buscam fazer do currículo uma ferramenta que mobilize corpos que aprendem em aprendizados úteis ao perseverar na existência em tempos de deterioração da vida.

Novamente recorremos à Ética de Spinoza, à teoria das linhas formulada por Deleuze em parceria com Guattari e ao nomadismo curricular da professora Sandra Mara Corazza. Nas obras pesquisadas encontramos elementos para pensar respostas adequadas àquilo que desejamos: postular princípios para criação de currículos que pretendem fazer da educação um processo alegre, amoroso e capaz de promover a união entre corpos por vínculos de amizade e; sintonizar as relações de ensino e aprendizagem na curiosidade, nos desejos de conhecer e criar dos corpos discentes que aprendem ao conviver e perseverar na existência nas zonas de intensidades de sua realidade.

Sabemos que o currículo é um instrumento inerte. Somente atravessado pelas linhas de força de um discurso que o qualifique, atribua sentidos, defina objetivos, prioridades e formas de educar consideradas adequadas aos desafios que postula para si é que poderemos dizer do que um currículo é capaz ou não.

Porque Spinoza não aborda os pormenores da educação em suas obras, encontramos no nomadismo curricular da professora Sandra Mara Corazza e em reflexões desenvolvidas por Deleuze em parceria com Félix Guattari princípios e práticas para criar modos de educar afetivos. Mesmo não tratando a Educação como um tema central em sua produção intelectual, o vocabulário pedagógico salta aos olhos quando Spinoza justifica a utilidade da sua filosofia 
naquilo que ela pode nos ensinar. Além disso, as proposições e reflexões que sustentam a Ética instituem um discurso em defesa da alegria, do amor e da liberdade de pensar segundo noções comuns concebidas a partir de ideias adequadas.

Para o indivíduo, a teoria do conhecimento spinozano ensina "a realizar apenas aquelas ações que o amor e a generosidade nos aconselham", e como nos conduzir diante da sorte, "quer dizer, frente àquelas coisas que não estão sob nosso poder" para, assim, aprendermos a "suportar com igual ânimo uma e outra face da fortuna" (SPINOZA, 2017, p. 94). Na esfera social da vida, a utilidade da filosofia de spinozana nos "ensina a ninguém odiar, desprezar, ridicularizar, invejar, nem com ninguém irritar-se"; também ensina a "cada um se contentar com o que tem e auxiliar ao próximo" fazendo uso adequado da razão "ou seja, de acordo com aquilo que a ocasião e as circunstâncias exigirem" (SPINOZA, 2017, p. 94).

O contentamento foi aqui entendido como um estado vibracional que todo e qualquer corpo pode - ao menos potencialmente - experimentar, de maneira singular: a máxima alegria possível diante das circunstâncias e das forças sociais que dão forma ao cotidiano que vivemos. Nada, portanto, tem a ver com uma posição submissa ou passiva diante de causas e efeitos das políticas de morte contemporâneas.

$\mathrm{Na}$ política, a utilidade da filosofia spinozana foi sustentada em nome da liberdade e da capacidade que ela possui de ensinar "como os cidadãos devem ser governados e dirigidos, não, evidentemente, para se tornarem escravos, mas para que, livremente, façam o que é melhor" (SPINOZA, 2017, p. 94). Mesmo não sendo fácil ensinar a Ética do filósofo seiscentista, pois, como ele mesmo adverte, trata-se de um exercício árduo e cotidiano, contudo, ele pode "ser encontrado. E deve ser certamente árduo aquilo que tão raramente se encontra" (SPINOZA, 2017, p. 238).

Como encontrar tais caminhos? Caminhando, sem dúvida. Nessa caminhada nossas ferramentas são os conceitos e os planos. Vejamos qual relação podemos estabelecer entre eles. Segundo Deleuze e Guattari (1999, p. 52), podemos compreender os conceitos como acontecimentos e o plano como "o horizonte dos acontecimentos, o reservatório, ou a reserva de acontecimentos puramente conceituais".

O conceito não conhece outra coisa senão a si mesmo. Podemos compreender o plano "como um deserto que os conceitos povoam sem partilhar. São os conceitos mesmos que são as únicas regiões do plano, mas é o plano que é o único suporte dos conceitos" (DELEUZE; GUATTARI, 1992, p. 52). Conceitos são zonas de intensidades do plano. Mas de que plano estamos falando? Comecemos falando do plano de imanência. 
[...] quando a imanência não é mais imanente a outra coisa senão a si que se pode falar de um plano de imanência. Um tal plano é talvez um empirismo radical [...]. Ele não apresenta senão acontecimentos, isto é, mundos possíveis enquanto conceitos, e outrem, como expressões de mundos possíveis ou personagens conceituais. $\mathrm{O}$ acontecimento não remete o vivido à um sujeito transcendente [...], mas remete, ao contrário, ao sobrevoo imanente de um campo sem sujeito; Outrem não devolve a transcendência a um outro eu, mas traz todo outro eu à imanência do campo sobrevoado. $\mathrm{O}$ empirismo não conhece senão acontecimentos (DELEUZE; GUATTARI, 1992, p. 64).

O acontecimento é da ordem do necessário. É único, não sendo possível repeti-lo. Aquilo que há de mais potente em um acontecimento é o agora, o atual. "O atual, o estado ou fazer atual, é o ponto para onde convergem todas as características necessárias da situação" (GAUTHIER, 1999, p. 17). Em um processo pedagógico que visa transformar a realidade que produz tristeza, passado, presente e futuro coexistem. É uma caraterística da natureza filosófica do tempo do plano de imanência: ele pressupõe a coexistência - de ideias, de modos de pensar, ser, estar no mundo. Esse tempo é o próprio "devir infinito da filosofia, que atravessa sua história mas não se confunde com ela"; filosofia como devir do pensamento, não falamos de planos que se sucedem, mas de planos que coexistem, que podem "ora se separar, ora se reunir - na verdade, tanto para o melhor, quanto para o pior" (DELEUZE; GUATTARI, 1992, p. 78).

É importante compreender que, gostemos ou não, todo "plano opera uma seleção do que cabe de direito ao pensamento", sendo esta seleção justamente "o que varia de um plano para outro" (DELEUZE; GUATTARI, 1992, p. 68). Para melhor ilustrar o que queremos dizer, voltemos nossa atenção à Europa medieval, cujo plano de imanência era predominantemente cristão. Naquela época, os modos de pensar e agir eram determinados por verdades produzidas e propaladas pelos sacerdotes que diziam conhecer as vontades e volições de um deus concebido à imagem e semelhança do homem.

Depois de uma série de acontecimentos históricos perturbarem o plano católico, os renascentistas, depois os iluministas e, posteriormente, os modernos, deram vida a um novo plano. Com ele, os defensores da razão modernizada disputaram com os clérigos o domínio sobre os regimes de produção de verdades, até então, divinizadas. Após a relativa perda de poder da igreja católica, os atritos entre os dois planos - cristão e moderno - foram amenizados e entraram em composição. Somaram-se na disseminação das premissas, preconceitos, verdades, ilusões e inadequações da nova razão moderna.

Em conjunto, os dois planos operaram a reconstrução da noção de Deus à imagem e semelhança do europeu médio, cujo modo de vida foi - por eles mesmos - postulado como 
superior aos demais modos de perseverar a existência dos povos do mundo. A diferença imanente ao ser humano foi hierarquizada segundo a cor da pele e traduzida como ingenuidade e inferioridade natural. Com a ilusória ideia de superioridade da cultura europeia, a imagem heroica do europeu cristão e moderno estava pronta para exportação em oposição à imagem do bárbaro incivilizado e corrompido moralmente.

Quando as grandes potências europeias partiram para as grandes navegações e pirataria "em nome de Deus, Ouro e Glória", iniciaram processo de destruição dos planos de populações originárias enquanto espoliaram recursos naturais e humanos à base da violência física e simbólica (ALTIERI et al., 2002, p. 23). Revestido de salvação dos povos bárbaros, o holocausto colonizador e o consequente apagamento das epistêmes dos povos colonizados homogeneizaram a diferença dos modos humanos de perceber e viver o mundo, em um processo que pode ser explicado resumidamente da seguinte maneira:

1. A civilização moderna autodescreve-se como mais desenvolvida e superior (o que significa sustentar inconscientemente uma posição eurocêntrica). 2. A superioridade obriga a desenvolver os mais primitivos, bárbaros, rudes, como exigência moral. 3. O caminho de tal processo educativo de desenvolvimento deve ser aquele seguido pela Europa (é, de fato, um desenvolvimento unilinear e à europeia o que determina, novamente de modo inconsciente, a "falácia desenvolvimentista"). 4. Como o bárbaro se opõe ao processo civilizador, a práxis moderna deve exercer em último caso a violência, se necessário for, para destruir os obstáculos dessa modernização (a guerra justa colonial). 5. Esta dominação produz vítimas (de muitas e variadas maneiras), violência que é interpretada como ato inevitável, e com o sentido quase-ritual de sacrifício; o herói civilizador reveste as suas próprias vítimas da condição de serem holocaustos de um sacrifício salvador (o índio colonizado, o escravo africano, a mulher, a destruição ecológica, etecetera). 6. Para o moderno, o bárbaro tem uma "culpa" (por opor-se ao processo civilizador) que permite à "Modernidade" apresentar-se não apenas como inocente mas como "emancipadora" dessa "culpa" de suas próprias vítimas. 7. Por último, e pelo caráter "civilizatório" da "Modernidade", interpretam como inevitáveis os sofrimentos ou sacrifícios (os custos) da "modernização" dos outros povos "atrasados" (imaturos), das outras raças escravizáveis, do outro sexo por ser frágil, etecetera (DUSSEL, 2000, p. 49).

A expansão do plano de imanência ocidental - cristão e moderno - pelo mundo suprimiu e desvalorizou, quando não extinguiu, outros planos e formas de pensar e agir sobre a realidade (GONÇALVES, 2016). Séculos depois, quando aportes conceituais potentes para pensar as causas e efeitos do holocausto colonizador afetaram o plano de imanência contemporâneo, é que foi possível, talvez com mais intensidade na academia, perceber e discutir as causas e efeitos daquele processo histórico de homogeneização cultural e laminação das subjetividades. 
À luz de novos conceitos, teorias e discursos que afetaram o plano de imanência globalizado, as causas e consequências do violento holocausto colonizador foram percebidas e denunciadas na atualização da mesma concepção de desenvolvimento econômico à europeia. Daí por diante, a proposição de mudanças efetivas na luta contra as políticas de mortes reproduzidas nas atualizações da mesma lógica colonial de exploração de pessoas e recursos naturais atingiram um novo patamar.

Por falta de tempo e espaço, não temos condições de expor os pormenores que sustentam necropolíticas contemporâneas como o racismo estrutural, a misoginia, a homofobia, a falácia desenvolvimentista etc. Sobre os efeitos desses novos conceitos no plano de imanência educacional recomendamos a leitura do livro de Tomaz Tadeu da Silva (2010): "Documentos de identidade: uma introdução às teorias do currículo". A obra traz um resumo histórico de acontecimentos reais e conceituais que, ao longo do tempo, (re)significaram o entendimento sobre o que é e o que pode um currículo quando confrontado por necropolíticas e outros processos de deterioração da existência.

Silva (2010) sistematizou os efeitos daquelas teorias e discursos dos povos mutilados na expansão do plano de imanência moderno no currículo. Apresentou um catálogo contendo diferentes perspectivas de uso da ideia de currículo enquanto instrumento pedagógico de formação humana e problematização da realidade. São conceitos potentes que impulsionaram insurgências contra mecanismos produtores e reprodutores de políticas de morte.

Ao dar nome àqueles males que enriqueceram e estruturam as sociedades modernas, foi subsidiada e fortalecida a luta contra os modos de promover a deterioração da existência humana e da natureza viva. Essa luta deve ter:

[...] como finalidade produzir a vida, derrubar hierarquias instituídas por aqueles que se acostumaram a vencer sem ter razão, tendo a "violência absoluta", nesse labor, uma função desintoxicadora e instituinte. Essa luta tem uma dimensão tripla. Visa [...] destruir o que destrói, amputa, desmembra, cega e provoca medo e cólera - o tornar-se coisa. Depois, tem por função acolher o lamento e o grito [...] daqueles e daquelas que, destituídos de si, foram condenados à abjeção; cuidar e, eventualmente, curar aqueles e aquelas que o poder feriu, violou, torturou ou, simplesmente, enlouqueceu (MBEMBE, 2018, p. 02).

Em síntese, nossa luta é uma luta contra toda forma de perpetuação e propagação de afetos de tristeza e de ódio. Segundo Spinoza, é apenas com amor que se pode desarmar o ódio, assim como é preciso alegria para refrear um afeto de tristeza. É uma questão filosófica. Um choque de planos que nos remete ao processo histórico propagandeado como sendo a luta entre a razão e a ignorância, a civilização e a barbárie, Deus e o Diabo. 
Finalmente podemos perceber que a propaganda moderna não era uma defesa da razão, da ciência, quer dizer, de um processo de pensar mais adequado e dinâmico que as sagradas escrituras de explicar as leis da existência - ou leis de Deus, da natureza, da substância criadora. Vemos que a expansão do plano de imanência científico e centrado na Europa pode ser compreendido como "um conflito entre a multiplicidade de saberes que se opunham entre si", no qual as nações europeias exerceram "seu 'poder disciplinador', operando por quatro procedimentos básicos: desqualificação/seleção; normalização; hierarquização; centralização piramidal" (GALLO, 2006, p. 557).

Nota-se, também, que o:

[...] impulso que deu origem à ciência moderna está ligado, em grande parte, ao conhecimento produzido no contexto dos interesses de exploração econômica do empreendimento colonial. [...]. A dimensão epistemológica e cultural do processo de dominação colonial não se limitava, entretanto, à produção de conhecimento sobre o sujeito colonizado e seu ambiente. O processo de dominação, na medida em que ia além da fase de exterminação e subjugação física, precisava afirmar-se culturalmente. [...]. O projeto colonial teve, desde o início, uma importante dimensão educacional e pedagógica. Era através dessa dimensão pedagógica e cultural que o conhecimento se ligava, mais uma vez, ao complexo das relações coloniais de poder (SILVA, 2010, p. 128).

E porque podemos aperfeiçoar os modos de conhecer e ensinar segundo premissas científicas, o que mudaríamos na educação que podemos praticar? Há uma passagem nas Três Ecologias (2001), de Félix Guattari, que nos ajuda a pensar tanto o que queremos e podemos fazer, quanto aquilo que devemos fazer para que a educação do nosso tempo participe do desarme das políticas de morte. Destacamos essa passagem em razão da acuracidade do autor francês na previsão do futuro. Trinta anos atrás, ele nos alertava sobre os perigos iminentes que enfrentaríamos hoje ao prever a escalada do "racismo, do fanatismo religioso, dos cismas nacionalitários caindo em fechamentos reacionários, os da exploração do trabalho das crianças e da opressão das mulheres[...]" (GUATTARI, 2001, p. 17).

Segundo o autor francês, a escalada daqueles perigos reflete uma crise de percepção que nos impede de compreender adequadamente a conexão e a complexidade dos problemas de nossa época. A percepção inadequada da realidade que herdamos dos modernos invasores europeus não foi, nem demonstra ser, capaz de solucionar o paradoxo lancinante onde os meios para solucionar os problemas sociais e ecológicos de nosso tempo já existem, contudo, esbarram na incapacidade coletiva de tornar esses meios operativos. Esbarra na incapacidade de democratizar o alcance do desenvolvimento social, econômico e ambiental. Esbarra em políticas de morte que produzem indiferença e reproduzem tristeza e ódio.

RIAEE - Revista Ibero-Americana de Estudos em Educação, Araraquara, v. 16, n. 4, p. 2826-2851, out./dez. 2021. e-ISSN: 1982-5587 
A partir do referencial teórico adotado discutiremos sobre princípios e práticas que nos ajudaram a fazer do currículo uma tecnologia social potente, capaz de gerar afetos de alegria e amor ao agir para transformar realidades que são causa e efeito de tristeza e ódio. Não podemos reproduzir inadequações do plano de imanência europeu que sustentam necropolíticas variadas. Simplesmente porque, entre pensadores que afetaram o plano de imanência moderno, aquelas inadequações já estavam superadas.

Queremos, também, um plano pedagógico adequado à complexidade dos desafios que a realidade brasileira impõe a educadores e educadoras que lutam contra políticas de morte de nosso tempo em variadas frentes. Um plano que seja singularizável em diferentes espaços e contextos. Para a elaboração desse plano listamos conceitos que nos permitem propor princípios e práticas curriculares para criação de currículos afetivos, que vagam pela realidade de quem aprende e considera o desejo de conhecer do corpo que padece, pensa e age na realidade.

\section{Dos “princípios" moleculares}

Pensamos quatro princípios de molecularidade para nos guiar neste plano de um currículo dos afetos, a saber: A educação será Ética baseada nos afetos de alegria e amor, perceber todos como parte de um, N-1; A imagem do conhecimento será rizomática; $\mathrm{O}$ currículo será nômade e o pensamento produzido pelo uso adequado da razão será livre; A produção de conhecimento será cartográfica e a cartografia mapeará aquilo que o corpo toca do plano de imanência.

Passamos então a perceber as linhas de forças que afetam o processo educativo. Há linhas de força em toda a parte, em todas as formas de existência e em todas as relações. Elas agem no esforço que faz da vida persistência, perseverar na existência. No terceiro volume de Mil Platôs, Deleuze e Guattari (2011- c) apontam três linhas de forças que afetam pessoas, grupos sociais, processos e instituições: linha dura ou molar; linha segmentação ou molecular; e linha abstrata ou de fuga.

$\mathrm{Na}$ primeira há muitas falas e conversações, questões ou respostas, intermináveis explicações, esclarecimentos; a segunda é feita de silêncios, de alusões, de subentendidos rápidos, que se oferecem à interpretação. Mas se a terceira fulgurará, se a linha de fuga é como um trem em marcha, é porque nela se salta linearmente, pode-se enfim falar aí "literalmente", de qualquer coisa, talo de erva, catástrofe ou sensação, em uma aceitação tranquila do que acontece em que nada pode mais valer por outra coisa (DELEUZE; GUATTARI, 2011a, p. 77). 
Embora produzam agenciamentos radicalmente diferentes, estas linhas não se dão necessariamente separadas ou em oposição. Ao contrário, elas coexistem, se alternam e se misturam o tempo todo. "Elas nos compõe, assim como compõe nossos mapas. Elas se transformam e podem mesmo penetrar uma na outra. Rizoma" (DELEUZE; GUATTARI, 2011a, p. 84).

As linhas de segmentaridade trazem consigo as expectativas próprias de modelos genéricos de existir e se portar na reprodução desses mesmos modelos em diferentes tempos, lugares e sociedades. A partir dela são construídos modelos estereotipados, cujos referenciais formam imagens e ideias a priori do ser que existe e, assim, definem o que se espera de cada tipo idealizado. São elas que definem, por exemplo, o modelo ideal de criança, de adolescente, de estudante, de profissional, de namorados/as, de casal, pais, mães, filhos e avós.

Modelos são moduladores, constroem padrões que, consequentemente, se tornam delimitadores de identidade, suprimindo, parcialmente, a subjetividade de seres reais. Esses segmentos formados por linhas duras estabelecem padrões de conduta, normas, regras de convivência explícitas e implícitas. Por essas linhas e seus respectivos modelos, normas e regras, indivíduos e coletividades, todos seremos observados, julgados e retificados.

Não é possível escapar das linhas duras sem consequências. Essas linhas parecem sempre triunfar. Mas não devemos categorizar esses tipos de linhas como ruins. Elas, inclusive, podem comportar "muita ternura e amor" (DELEUZE; GUATTARI, 2011a, p. 74). A padronização estabelecida pelas linhas duras faz a vida parecer previsível, normal, rotineira, linear, afinal, são linhas de garantia e controle da "identidade de cada instância, incluindo aí a identidade pessoal", que estabelecem "um jogo de territórios bem definidos, determinados, planejados. Tem-se um porvir "que diz o que é próprio da zona de normalidade e o que é desviante." (DELEUZE; GUATTARI, 2011a, p. 73)

As linhas de segmentação molecular contêm forças de desterritorialização que produzem diferenças mais ou menos toleráveis, a partir das métricas de comparação embutidas nos modelos de referência definidos por linhas duras. Pelas linhas moleculares, é possível fazer passar fluxos que tornam os segmentos e os modelos menos evidentes e localizáveis e julgamentos de valor mais complexos.

Radicalmente diferente às duas anteriores, a linha de fuga é de outra natureza. Imprevisível, comporta perigos diferentes, visto que não "admite qualquer segmento, e que é, antes, como que a explosão das duas séries segmentares", podendo causar desterritorializações parciais e absolutas (DELEUZE; GUATTARI, 2011a, p. 76). Ela 
também não admite as métricas de comparação tecidas por linhas molares e toleradas pelas linhas moleculares. Não aceita julgamentos morais. Forças de vida e de morte, de criação e reprodução, estão represadas nas linhas de fuga.

[...] não seria esta inteiramente pessoal, maneira pela qual um indivíduo foge, por conta própria, foge "as suas responsabilidades", foge do mundo, se refugia no deserto ou ainda na arte... etc. Falsa impressão. [...] Quanto às linhas de fuga, estas não consistem nunca em fugir do mundo, mas antes fazê-lo fugir (DELEUZE; GUATTARI, 2011a, p. 85).

Para melhor compreendê-las, jamais podemos olhar para uma ou outra de modo isolado. Uma remete à outra. As três linhas, de naturezas distintas, estão em composição. Estão vivas. Criam, atualizam e destroem regras da coesão e regulação social. Um jogo entre movimento e repouso que produz diferença e repetição. Criam e destroem padrões. Desenham territórios existenciais e que conduzem a forma como pensamos, somos afetados e nos constituímos enquanto seres singulares.

Utilizamos a noção de afeto não no sentido coloquial da palavra, mas no sentido conceitual proposto por Spinoza. Ele considera que todo o corpo é afetado por três afetos primários - desejo, alegria e tristeza - os quais, por sua vez, dão origem aos demais afetos que um corpo é capaz de experimentar.

Os afetos alegria e tristeza são passagens. O primeiro deles é um afeto que aumenta nossa potência de agir e pensar. Corresponde à passagem de uma pessoa qualquer de uma perfeição menor a uma perfeição menor. A tristeza, afeto contrário à alegria, diminui nossa potência duplicada, de agir e pensar e, por consequência, diminui a perfeição de um corpo vivo. Já o desejo compreende "todos os esforços, todos os impulsos, apetites e volições do homem, que variam de acordo com o seu variável estado" (SPINOZA, 2017, p. 141).

A tristeza se refere àquelas que diminuem a nossa potência - de agir e pensar -, enquanto as alegres tratariam das afecções que aumentam ou estimulam a nossa potência.

Ressaltamos ainda que a alegria, para Spinoza, está associada a afetos adequados, aqueles que são razão ou causa de si. Já as paixões tristes, provindas de causa externas, seriam inadequadas, por produzirem uma mente que padece à ação. "Digo que agimos quando, em nós ou fora de nós sucede algo de que somos causa adequada, isto é, quando de nossa natureza se segue, em nós ou fora de nós, algo que pode ser compreendido clara e distintamente por ela só.” (SPINOZA, 2009, p. 98). Partindo deste entendimento é que propomos a ideia de um ensino afetivo, pautado em estímulos alegres. 
Em atividades dentro e fora da escola coordenávamos uma oficina de Educação Ambiental afetada pela abordagem agroecológica, no município de Ribeirópolis, interior do estado de Sergipe. De fato, o aprendizado necessário à compreensão das linhas de força inerentes a um modo de educar afetivo e aberto à diferença se seguiu de testes de ferramentas metodológicas comuns ao arcabouço teórico e prático da Agroecologia. Posteriormente, ao longo de mais de dois anos de atividades, aquele modo de educar passou por uma série de desengates das particularidades e desafios que a abordagem agroecológica traz consigo.

A integração de diferentes metodologias em uma proposta curricular apresentou potencial de singularizar as relações de ensino e aprendizagens em projetos pedagógicos concebidos segundo aquilo que os corpos discentes desejavam saber. Tomado por uma conduta afetiva, o currículo em criação seguiu uma trajetória diferente da esperada quando a Agroecologia aborda a problemática da deterioração da existência na produção e distribuição de alimentos.

Dadas as características da oficina - sem provas, notas, atividades obrigatórias - e do perfil de professor - com pouca tendência à adoção de atitudes punitivas (enviar estudantes à direção, solicitar advertências, suspensões ou expulsão) - seguimos um caminho próprio: conectar as atividades propostas àquilo que despertava desejo ou curiosidade no corpo discente. Incorporamos à proposta curricular algumas diretrizes e princípios da pedagogia de projetos, ou aprendizagem baseada em projetos, nas atualizações da oficina de Educação Ambiental afetada pela Agroecologia.

Nas atualizações da proposta curricular abandonamos livros e manuais de decalque e deixamos de lado seus roteiros, suas perguntas e respostas prontas. Atentamos para questões de maior relevância e potência pedagógica: aquelas que provocavam os corpos discentes. Sem, ou com o mínimo de interferência da nossa parte, pessoas que ocupavam o lugar de docência, a intencionalidade dos projetos seguia as linhas de força afetivas de realidades por onde nosso currículo vagava.

Ao final de um dos projetos pedagógicos planejados e geridos com base naquela incipiente proposta curricular, uma sala abandonada pelo poder público há mais de sete anos foi revitalizada e convertida em um singela biblioteca e brinquedoteca onde as crianças podiam estudar e se divertir com segurança. Nomeada Segunda Casa, aquela pequena sala revitalizada era causa de afetos de alegria que, mesmo que momentaneamente, fazia as crianças, jovens e seus familiares deixarem de lado a tristeza imanente ao processo de deterioração da existência (CANTANHEDE; LIBÓRIO, 2018). 
Dentre os demais projetos desenvolvidos, o que relatamos acima destacou-se pelo contexto social que determinou sua intencionalidade e os últimos ajustes metodológicos decorrentes da abertura afetiva do currículo e reinvenção e singularização das relações de ensino e aprendizagem como estratégia de enfrentamento de realidades tristes e de ódio. Quando levada em consideração a desigualdade social brasileira, os desafios impostos às pessoas que compõem e contribuem com o fortalecimento das comunidades escolares são ainda maiores. Exigem modos de lidar com a tristeza e ódio que, por descuido ou incapacidade de lutarmos contra elas, aceitamos como normais.

\section{Porque pode ser diferente... pesquisa, ciência e cartografia}

Transformar, pedagogicamente, uma realidade que desejamos diferente requer pensar, propor e conduzir uma educação menor, localizada. E, para isso, ela deve ser afetiva. Ao falarmos em menor, estamos nos referindo a esses modos de educar que se deparam com os mecanismos de laminação de subjetividade comuns à Educação Maior, regulada e padronizada pelos órgãos de governo.

Perguntar e responder cientificamente nos coloca em uma dinâmica de ritos sociais operadora da normatização das relações de ensino e aprendizagens comuns aos modos do conhecer científico. Para Maturana e Varela (1995), uma crítica será científica apenas se estiver em consonância com normais gerais que compreendem, ao menos, quatro condições constitutivas:

a. Descrição do ou dos fenômenos a serem explicados de forma aceitável para a comunidade de observadores. b. Proposição de um sistema conceitual capaz de gerar o fenômeno a ser explicado de maneira aceitável para a comunidade de observadores (hipótese explicativa). c. Dedução, a partir de b, de outros fenômenos não considerados explicitamente na proposição, bem como a descrição de suas condições de observação na comunidade de observadores. d. Observação desses outros fenômenos deduzidos a partir de b (MATURANA; VARELA, 1995, p. 70).

As quatro condições descritas acima são basilares e aceitas previamente por todos os modos de conhecer na academia. As especificidades comuns às comunidades de observadores produzem diferença ao singularizar, qualificar modos de conhecer e comunicar verdades científicas. Podemos compreender a ciência, em seus diversos modos de produzir verdades científicas, como agenciamentos. Isto é, como multiplicidades que selecionam suas teorias, hipóteses, conceitos, princípios, práticas e noções comuns. 
Qualquer modo de compreender a realidade, científico ou não, é composto por "linhas de articulação, ou segmentaridade, estratos, territorialidades, mas também linhas de fuga, movimentos de desterritorialização e desestratificação" (DELEUZE; GUATTARI, 2011a, p. 18). São essas linhas e seus movimentos que, bom ou ruim, padronizam e produzem diferença nas comunidades de observadores. A produção de diferença na ciência faz com que possamos compreender muitas coisas, algumas de modos diferentes, umas mais adequadas, outras menos.

Entre as adequações e inadequações das ideias, teorias e discursos científicos, compreenderemos coisas, fatos e processos adequada e inadequadamente. As limitações inerentes ao conhecer científico não acompanham a velocidade do pensamento e a acelerada produção e comunicação do conhecimento nos dias de hoje.

Ao reconhecer as adequações, inadequações, alcance e limitações próprias do conhecer científico, instaura-se um processo dinâmico de ordenação do complexo e caótico pensamento. Os modos de conhecer emergentes do sistema explicativo da ciência são, por consequência, falhos e suscetíveis às vontades humanas. Reconhecer as características e as limitações do lugar de onde falamos não é demonstração de fraqueza desse modo de conhecer. Pelo contrário, é sua fortaleza. A dúvida é anterior à certeza. Em movimento pelo plano onde residem os conceitos, a produção do conhecimento pelo uso adequado da razão é uma procura incessante por ideias adequadas que expliquem as leis da natureza. Há, contudo, uma potência imanente ao pensamento que faz das ideias um afeto vivo.

As ideias não morrem. Não que elas sobrevivam simplesmente a título de arcaísmos. Mas, num certo momento, elas puderam atingir um estágio científico, e depois perdê-lo, ou então emigrar para outras ciências. Elas podem então mudar de aplicação e de estatuto, podem até mudar de forma e de conteúdo, mas guardam algo de essencial no encaminhamento, no deslocamento, na repartição de um novo domínio. As ideias sempre voltam a servir, porque sempre serviram, mas de modos atuais os mais diferentes. [...]. A história das ideias nunca deveria ser contínua; deveria resguardara-se das semelhanças, mas também das descendências ou filiações, para contentar-se em marcar os limiares que uma ideia atravessa, as viagens que ela faz, que mudam sua natureza ou seu objeto (DELEUZE; GUATTARI, 2011d, p. 14$15)$.

A cartografia, compreendida à luz e à sombra das ideias de Deleuze e Guattari, é um exemplo claro disso. Desterritorializada da Geografia ela é convertida em uma aposta metodológica. Assumimos o risco de entendê-la mais como uma ética e estética de pesquisar, estudar e escrever do que como um método científico detalhado à exaustão. Todo trabalho científico é um ato de criação: quando inspirados nessa definição de cartografia, assumimos 
um outro modo de estar em meio aos acontecimentos e agenciamentos que nos afetam enquanto pesquisamos e explicamos as linhas de força que sentimos junto das linhas escritas que lemos ou escrevemos - escrileitura (CORAZZA, 2014).

Embora seja possível notar um certo distanciamento filosófico do método cartesiano clássico quando negamos a ilusão da neutralidade científica, a cartografia não defende o abandono das normas basilares do sistema explicativo científico. Fazendo uso de ferramentas de pesquisa já consolidadas - entrevistas, diários de campo, gravadores, transcrições decidimos não fazer a observação refém de ilusões, e nos afastamos dos decalques investigativos que "fazem a diversidade desaparecer da percepção e, consequentemente, do mundo" (SHIVA, 2003, p. 15).

Quando a ideia subjacente à arte da produção de mapas migra para um novo estatuto de investigação e criação científica, nos deparamos com outros desafios, limites e possibilidades. Privilegiamos o estudo dos agenciamentos coletivos de enunciação e agenciamentos maquínicos do desejo, dos acontecimentos, das correlações, dos momentos e modos que vivemos.

Nesse sentido, escrever "nada tem a ver com significar, mas agrimensar, cartografar, mesmo que sejam regiões ainda por vir" (DELEUZE; GUATTARI, 2011b, p. 19). Essa compreensão do mundo que se espalha enquanto forma uma comunidade de observadoras e observadores mais aberta à diferença "cria uma nova circulação de afetos, expõe o virtual presente no atual, gera saberes inesperados". A dificuldade desse caminho, prossegue Guathier (1999, p. 15), “é que esses saberes passam como fluxos, não são identificáveis segundo os hábitos acadêmicos do pensamento."

Ainda juntos de Gauthier (1999, p. 14), assumimos que cartografia é um modo de pesquisar, "é criar devires, exprimir o virtual incluído em uma situação; lançar mão de multiplicidades". Em decorrência desse tipo de entrada no conhecimento, devemos estar atentos à "poiesis da natureza e da vida social, a seu poder de autocriação e às implicações do nosso olhar chamado científico, nesse processo de criação.” (GAUTHIER, 1999, p. 15).

Para ele, "fazer-ciência, aprender, logo ensinar, cuidar", educar, quer dizer, todas as relações que temos com o saber são múltiplas plurais; existem, portanto, multiplicidades de "entradas no conhecimento", ora em composição, ora em atrito (GAUTHIER, 1999, p. 20). Porque desejamos subsidiar modos de educar que visam transformar realidades tristes e odiosas em realidades alegres e amorosas, mapearemos linhas de força e inter-relações entre o passado, o presente e o futuro que um acontecimento ou agenciamentos comportam. 
A entrada escolhida por nós na aposta de um currículo afetivo, assim como os caminhos tomados e o modo de caminhar, quer dizer, de fazer ciência, serão indissociáveis do conhecimento produzido. Cartografar, na perspectiva aqui adotada, é processo. É desenhar, mapear, construir territórios em linhas maleáveis descontínuas e, ao mesmo, interligadas em um tear, que não se sabe necessariamente o início e o fim, mas que ganha materialidade e sentidos a partir dos planos de composição que este possa vir a configurar. Cartografia é fazer rizoma. É um entrelaçar de conceitos extraídos do plano de imanência na produção de algo singular.

Ao adotarmos a ideia de cartografia, buscamos as aproximações com o conceito de rizoma de Deleuze e Guattari $(2011$ b, p. 23$)$, que questionam a noção arbórea tradicional e fragmentada do pensamento. Isso porque,

Há sempre algo de genealógico numa árvore, não é um método popular. Ao contrário, um método de tipo rizoma é obrigado a analisar a linguagem efetuando um descentramento sobre outras dimensões e outros registros. Uma linguagem não se fecha sobre si mesma senão em uma função de impotência.

Um pensamento jamais parte de uma ideia isolada em si. Nunca se sabe por onde ele começa, pois toda e qualquer ideia já nasce atrelada às incontáveis experimentações, afetos e acontecimentos que atravessaram, e seguem atravessando, o corpo que o pensa. Tudo que existe e que se pensa está em relação a algo, atrelado a um grande e imensurável conjunto de referências vagando na virtualidade da mente e que, na construção de um pensamento, são atualizadas, formando novos entendimentos imagéticos, convertidos, por fim, em linguagem. Multiplicidade de línguas vivas, de gírias e patoás.

Porque mapeia fluxos de acontecimentos, a produção de mapas conceituais escapa a qualquer lógica estruturante, rígida ou hierárquica, pois não tem juízo de valor. Ela é costura e, assim como numa tecitura, todo e qualquer ponto é indispensável na composição das linhas e amarras, na produção de diferença.

Num rizoma, [...] cada traço não remete necessariamente a um traço linguístico: cadeias semióticas de toda a natureza são aí conectadas a modos de codificação muito diversos, cadeias biológicas, políticas, econômicas e etc., colocando em jogo não somente regimes de signos diferentes, mas também estatutos de estados de coisas. [...] Um rizoma não cessaria de conectar cadeias semióticas, organizações de poder, ocorrências que remetem às artes, às ciências, às lutas sociais. Uma cadeia semiótica é como um tubérculo que aglomera atos muito diversos, linguísticos, mas também perceptivos, mímicos, gestuais, cogitativos: não existe língua em si, nem universalidade da linguagem, mas concurso de dialetos, de patoás, de gírias, de línguas especiais (DELEUZE; GUATTARI, 2011b, p. 22).

RIAEE - Revista Ibero-Americana de Estudos em Educação, Araraquara, v. 16, n. 4, p. 2826-2851, out./dez. 2021. e-ISSN: 1982-5587 
Em outras palavras, a linguagem é viva, mutável e instável, da mesma maneira o pensamento rizomático, que se desdobra, redobra, ramifica. A árvore como metáfora do pensamento, composto por uma semente-ideia da qual floresceria todo um conhecimento considerado válido e científico, reforça os paradigmas que envolvem a ideia de verdade, não mais universal e absoluta, mas a que produz valor, coordena ações, comportamentos e estabelece e desloca centros de poder. Lembremos Foucault quando nos alerta que poder e saber estão sempre imbricados, no sentido de que "não há relação de poder sem a constituição correlata de um campo de saber, nem saber que não suponha e não constitua, ao mesmo tempo, relações de poder" (FOUCAULT, 1977, p. 30). É desta imbricação que também se vale a legitimidade reservada aos textos científicos e às pesquisas acadêmicas, pois na lógica foucaultiana o poder-saber mais se exerce, como uma estratégia, do mais do que se possuir, como uma propriedade.

Para Deleuze e Guattari, o pensamento funciona de forma rizomática agenciando corpos. A leitura de um livro também. Por isso eles recomendam não perguntar o que um texto quer dizer ou significa, mas questionar como e "com o que ele funciona, em conexão com o que ele faz passar ou não intensidades, em que multiplicidades ele se introduz e metamorfoseia a sua" (DELEUZE; GUATTARI, 2011b, p. 18). Uma leitura é sempre geradora de pensamento, de construção imagética e de associações com todas as outras referências da mente. A leitura está sempre em relação à multiplicidade que constitui o leitor, sendo ela, anteriormente, composição da singularidade de quem a escreve. São processos que formam teias densas de associações cognitivas e assimilações de conhecimento. O mesmo livro produzirá sempre afetos singulares a cada leitura, pois, por experiência sabemos que "a mente não é capaz de pensar, a cada vez, de maneira igual, sobre um mesmo objeto; em vez disso, a mente é tanto mais capaz de considerar este ou aquele objeto, quanto mais o corpo é estimulado pela imagem deste ou daquele objeto" (SPINOZA, 2009, p. 101).

Tomemos como exemplo o clássico da literatura brasileira, "Dom Casmurro", de Machado de Assis (1839-1908), para ilustrar o que podemos entender sobre um livro rizomático. A trama entre as personagens principais do livro desperta e mantém uma dúvida que agenciará os corpos que leem o livro de diferentes maneiras: teria Capitu traído Bentinho? Não faz sentido perguntar o que pensava o autor do livro enquanto escrevia suas linhas. É um livro que provoca diferentes afetos. E aí, nesse ponto, de produzir afetos reside a potência do livro. 


\section{Buscando uma possível conclusão: Multiplicidade e a potência dos afetos}

Toda escrita, assim como qualquer narrativa - seja em um livro, uma história, um filme, etc. - produz agenciamentos, que se reverte em afetos, e quanto mais um corpo é capaz de uma pluralidade de afetos, mais capaz será a mente de construir cognições múltiplas e compreender a realidade que experimenta. A singularidade de um corpo depende, diretamente, das suas multiplicidades, haja vista que são os elementos que o diferem de outros corpos o que aumenta a sua capacidade de singular e sua potência de agir. Provocar corpos que percorrem suas zonas de intensidades; possibilitar compreensões múltiplas e singulares de suas linhas, escritas e de força.

Por isso a defesa de que a captura da realidade, ou melhor, a dupla captura da realidade em que se vive, seja cartográfica. Porque ela permite captar o que um corpo, ou vários corpos em relação, alcança do plano de imanência. E quanto mais afetos ele toca maior é o "crescimento das dimensões numa multiplicidade que muda de natureza à medida que ela aumenta suas conexões" (DELEUZE; GUATTARI, 2011b, p. 24).

Contra as estruturas arborescentes que imobilizam o pensamento como sinônimo de verdade última os filósofos trazem a diferença imanente às multiplicidades como meio de expansão do rizoma, por aumento das leis de combinação. Isso porque "toda vez que uma multiplicidade se encontra presa a uma estrutura, seu crescimento é compensado por uma redução das leis de combinação" do pensamento (DELEUZE; GUATTARI, 2011b, p. 21).

Como seres relacionais, que se constituem em relação ao externo e aos acontecimentos, a nossa multiplicidade está sempre atrelada à nossa capacidade de afetar e ser afetado, assim como à nossa potência de agir. Recordemos que Spinoza entende que os afetos alegres são aqueles que aumentam a nossa potência de ação, enquanto os afetos tristes seriam os que nos colocam em posição passiva. Da mesma forma, "as multiplicidades se definem pelo fora: pela linha abstrata, linha de fuga ou de desterritorialização segundo a qual elas mudam de natureza ao se conectarem às outras" (DELEUZE; GUATTARI, 2011b, p. 25). Em um estudo cartográfico, toda multiplicidade será definida pelas linhas, conceitos, agenciamentos e dimensões que ela comporta em intenção (DELEUZE; GUATTARI, 2011b).

Para a construção de uma metodologia de ensino aberta aos afetos e às forças rizomáticas do pensamento, deve-se evitar recair em lógicas binárias que fixam posições dicotômicas e hierárquicas. Devemos também refutar eixos genéticos, dimensões suplementares e de transcendência, modelos, posições fixas de árvores e raízes que dividem, isolam o conhecimento em segmentos e disciplinas fechadas e pouco comunicantes.

RIAEE - Revista Ibero-Americana de Estudos em Educação, Araraquara, v. 16, n. 4, p. 2826-2851, out./dez. 2021. e-ISSN: 1982-5587 
É preciso fazer o múltiplo, não acrescentando sempre uma dimensão superior, mas, ao contrário, de maneira simples, com força de sobriedade, no nível das dimensões de que se dispõe, sempre n-1 (é somente assim que o uno faz parte do múltiplo, estando sempre subtraído dele). Subtrair o único da multiplicidade a ser construída; escrever a n-1. Um tal sistema poderia ser chamado de rizoma (DELEUZE; GUATTARI, 2011b, p.21).

Rupturas abrem o rizoma. As experimentações e criações fazem o pensamento conectar-se àquilo que afeta o corpo que pensa, sempre de modo singular, único e sem repetição. Procedendo por fugas e reterritorializações, as rupturas assiginificantes fazem o rizoma "aumentar seu território por desterritorialização" (DELEUZE; GUATTARI, 2011b, p. 28). O decalque de ideias, até na cartografia, reduz as leis de combinação do pensamento. Redução compensada pelo incremento naquelas mesmas leis enquanto a cartografia proporciona experimentações possíveis na produção rizomática de um mapa de intensidades.

Se o mapa se opõe ao decalque é por estar inteiramente voltado para uma experimentação ancorada no real. [...] Ele faz parte do rizoma. O mapa é aberto, é conectável em todas as suas dimensões, desmontável, reversível, suscetível de receber modificações constantemente. Ele pode ser rasgado, revertido, adaptar-se a montagens de qualquer natureza, ser preparado por um indivíduo, um grupo, uma formação social. Pode-se desenhá-lo numa parede, concebê-lo como obra de arte, construí-lo como uma ação política ou como uma meditação (DELEUZE; GUATTARI, 2011b, p. 30).

Decalcamos e reproduzimos ideias ao discursar sobre os movimentos e agenciamentos curriculares vivenciados outrora. Concatenamos ideias para ordenar conceitualmente o caótico agenciamento curricular da experiência pedagógica cartografada. Sem a temporalidade dos encontros físicos, os agenciamentos conectam-se entre si, com lugares, sabores, recordações, fatos, cores, cheiros, dores e amores ancorados em fatos e afetos, presentes e passados.

A proposta de uma metodologia cartográfica, que acolha o pensamento e a diferença em toda sua complexidade rizomática não invalida outras metodologias, nem mesmo a lógica do pensamento arbóreo. Não há oposição entre rizoma e árvore/raiz. Essa lógica binária e dicotômica não encontra lugar no plano. O rizoma possui entradas múltiplas, pelas quais podemos entrar e sair. Afinal, também:

[...] existem estruturas de árvore ou de raízes nos rizomas, mas, inversamente, um galho de árvore ou uma divisão de raiz podem recomeçar a brotar no rizoma. A demarcação não depende aqui de análises teóricas que impliquem universais, mas de uma pragmática que compõe as multiplicidades ou conjuntos de intensidades. No coração de uma árvore, no oco de uma raiz ou na axila de um galho, um novo rizoma pode se formar. 
Ou então é um elemento microscópico da árvore raiz, um radícula, que incita a produção de um rizoma (DELEUZE; GUATTARI, 2011b, p. 33).

Assim como a cartografia, o pensamento implica a construção de territórios e, considerando que aqui estamos falando de cartografia a partir da noção de rizoma, é preciso estar atento para outra questão. Se defendermos que o pensamento não se limita à lógica arbórea, que parte de um centro único de determinação, mas atrelado a indefinidas conexões afetivas, podemos entender que ele forma um território, múltiplos territórios. Quando temos uma ideia, esta ocupa um lugar plano de consistência composto por todas as referências e afetos que, para nós, estão associadas a ela. Logo, para poder se propor uma mudança curricular, atrelada não apenas a uma simples alteração metodológica, mas nos devires que envolvem os processos de ensino e aprendizagem, antes é necessária uma desterritorialização dos métodos que a precedem. Lembramos que qualquer reterritorialização implica em um processo de desterritorialização, e existe um abismo neste entre, um vazio não vazio, que é o momento de maior possibilidade de potência. Porque é na ruptura que se pode a mudança e, nela, a criação. É neste abismo que o agenciamento das afecções vai determinar a dimensão dos afetos, aumentando ou diminuindo os graus de potência do corpo.

$\mathrm{Na}$ teoria espinosiana, um corpo refreado reduz a sua potência de agir, produzindo tristeza, assim como um corpo estimulado tem sua potência aumentada. O mesmo acontece com o pensamento, pois, "se uma coisa aumenta ou diminui, estimula ou refreia a potência de agir de nosso corpo, a ideia dessa coisa aumenta ou diminui, estimula ou refreia a potência de pensar de nossa mente" (SPINOZA, 2009, p. 106). Pautado nisso que defendemos um currículo afetivo, no sentido de que estimular paixões alegres aumentem a potência de agir e, consequentemente, a potência de pensar.

Como na reforma de um imóvel, em que partes da estrutura que desejamos mudadas são preservadas para não ocorrer um desmoronamento absoluto, um processo de reformulação curricular tende a preservar algumas estruturas já existentes, caso contrário, não estaríamos falando em reformulação. A própria ideia de uma reterritorialização traz com ela a ideia de uma transformação de algum território já existente, e não de algo inédito, caso contrário seria simplesmente uma territorialização. Um pensamento rizomático jamais ignora as afecções prévias de um corpo, nem mesmo se pudéssemos apagar a memória consciente de alguém, ainda assim, esta pessoa construiria seus pensamentos a partir de outros campos perceptivos do corpo, como o inconsciente, a intuição e de tantos outros sensores informacionais que compõem a existência. 
É necessário guardar o suficiente do organismo para que ele se recomponha a cada aurora; pequenas provisões de significância e de interpretação, é também necessário conservar, inclusive para opô-las a seu próprio sistema, quando as circunstâncias o exigirem, quando as coisas, as pessoas, inclusive as situações nos obrigam; e pequenas rações de subjetividade, é preciso conservar suficientemente para poder responder à realidade dominante. (DELEUZE; GUATTARI, 2011b, p. 26).

A proposta de um currículo que priorize a produção de afetos alegres, estimulando e aumentando a potência de agir é, antes de tudo, reconhecer a diferença e a multiplicidade como força de vida. É produzir estruturas e estratos para que as linhas de fuga os explodam em desejos de criação. Criação de diferenças, singularidades, e transformação de significados e palavras na compreensão daquilo que nos é comum: a existência compartilhada e as múltiplas formas de percebê-la e vivê-la.

\section{REFERÊNCIAS}

ALTIERI, M. et al. Agroecologia: bases científicas para uma agricultura sustentável. 3. ed. Ver. ampl. São Paulo: Expressão Popular, AS-PTA, 2002. 592 p.

CANTANHEDE, C.; LIBÓRIO, P. Segunda Casa: a construção de uma proposta de educação em agroecologia para crianças. Cadernos de Agroecologia, v. 13, n. 1, 2018. ISSN 22367934

CORAZZA, S. M. et al. Escrileituras: um modo de ler-escrever em meio à vida. Educaçao e pesquisa, São Paulo, v. 4, n. 4, p. 1029-1043, 2014. Disponível em:

https://www.scielo.br/j/ep/a/9shzjMpKnNGtLwdS3V9Z54L/?format=pdf\&lang=pt. Acesso em: 18 jun. 2018.

DELEUZE, G.; GUATTARI, F. O que é a filosofia? Trad. Bento Prado Jr. e Alberto Alonso Muñoz. 1. ed. Rio de Janeiro: Editora 34, 1992.

DELEUZE, G.; GUATTARI, F. Mil platôs: capitalismo e esquizofrenia. Vol. 1. Trad. Ana Lúcia de Oliveira, Aurélio Guerra Neto e Celia Pinto Costa. 2 ed. São Paulo: Editora 34, $2011 b$.

DELEUZE, G.; GUATTARI, F. Mil platôs: capitalismo e esquizofrenia. Vol. 3. Trad. Aurélio Guerra Neto, Ana Lúcia de Oliveira, Lúcia Cláudia Leão e Suely Rolnik. 2 ed. São Paulo: Editora 34, 2012a.

DELEUZE, G.; GUATTARI, F. Mil platôs: capitalismo e esquizofrenia. Vol. 4. Trad. Suely Rolnik. 2 ed. São Paulo: Editora 34, 2012 b.

DUSSEL, E. Europa, modernidade e eurocentrismo. In: LANDER, E. (org.). A colonialidade do saber: eurocentrismo e ciências sociais, perspectivas latino-americanas. Buenos Aires: Clacso, Conselho Latinoamericano de Ciências Sociais, 2005. Disponível em: https://ufrb.edu.br/educacaodocampocfp/images/Edgardo-Lander-org-A-Colonialidade-do- 
Saber-eurocentrismo-e-ciC3AAncias-sociais-perspectivas-latinoamericanas-LIVRO.pdf. Acesso em: 25 out. 2019.

FOUCAUlT, M. Vigiar e Punir. Trad. Raquel Ramalhete. 20. ed. Petrópolis: Vozes, 1997.

GALLO, S. Modernidade/pós-modernidade: tensões e repercussões na produção de conhecimento em educação. Educação e Pesquisa, São Paulo, v. 32, n. 3, p. 551-565, 2006.

GAUTHIER, C. Esquizoanálise do currículo. Educação \& Realidade, Porto Alegre, v. 27, n. 2, p. 143-155, 2002.

GAUTHIER, J. O que é pesquisar-entre Deleuze-Guattari e o candomblé, pensando mito, ciência, arte e culturas de resistência. Educação \& Sociedade, Campinas, v. 20, p. 13-33, 1999.

GONÇÁLVES, R. A superioridade racial em Imanuel Kant: as justificações da dominação europeia e as suas implicações na América Latina. Kínesis, Marília, v. 7, n. 13, 2015.

GUATTARI, F. As três ecologias. São Paulo: Ed. Campinas \& Papirus, 2001.

MATURANA, H.; VARELA, F. A árvore do conhecimento. 1. ed. Campinas: Editorial Psy II, 1995.

MBEMBE, A. Necropolítica: Biopoder, soberania, estado de exceção, política da morte. Trad. Renata Santini. 1. ed. São Paulo: Edições, 2018. 80 p.

SHIVA, V. Monoculturas da mente: perspectivas da biodiversidade e da biotecnologia. 1. ed. São Paulo: Gaia, 2003. 240 p.

SILVA, T. Documentos de identidade: uma introdução às teorias do currículo. 2. ed. Bello Horizonte: Autêntica, 2010. 156 p.

SPINOZA, B. Ética. Trad. Tomaz Tadeu. 2. ed. Belo Horizonte: Autêntica, 2017. 


\section{Como referenciar este artigo}

FELDENS, D. G.; CATANHEDE, C.; FUSARO, L. O que pode um currículo? Breve ensaio sobre o currículo em imanência. Revista Ibero-Americana de Estudos em Educação, Araraquara, v. 16, n. 4, p. 2826-2851, out./dez. 2021. e-ISSN: 1982-5587. DOI: https://doi.org/10.21723/riaee.v16i4.15689

Submetido em: 01/08/2021

Revisões requeridas em: 25/09/2021

Aprovado em: 01/10/2021

Publicado em: 21/10/2021 